\title{
Developing Effective Instructional Skills: The Master Educator Program at SUNY Buffalo State
}

\section{Lorena D. Mathien}

Business Department, State University of New York Buffalo State, United States.

\begin{abstract}
With higher education facing budget cuts and declining enrollment, instructor effectiveness continues to be crucial, particularly in a state of increasing workloads with restricted resources. However, the dilemma of how to develop effective instructional skills while still maintaining a research agenda stems from a larger contradiction within professional disciplines; teaching is essential to the profession but holds a devalued position compared to research. It is not enough for an educator to recognize that teaching and research are mutually reinforcing, universities must also recognize and support this reality. Understanding that we must learn to be good instructors, even as teaching is devalued, led our School of Professions (SOP) to reflect on how we can develop strategies for becoming effective educators while still fulfilling our research (and service) agenda. With the Master Educator (MEP) program, our school is developing internal talent via instructional coaching between our School of Education (SOE) and our School of Professions. Research indicates that traditional forms of professional development are not effective. In turn, research on instructional coaching in $K-12$ setting has indicated a much higher implementation rate than traditional approaches to professional development; however, to our knowledge, there have been no attempts at implementing instructional coaching at the university level. The MEP is the first program to implement this practice at the university level.
\end{abstract}

Keywords:; Business; Education; Instructional Coaching; Mentoring. 


\section{Introduction}

Current conditions in the United States indicate continued higher education budget cuts in many states, and thus, teacher effectiveness continues to be crucial in a realm of potentially increased workloads with constrained resources (Roach, 2014). Much of the research involving quality of teaching in post-secondary business is based on student perceptions, with scarce literature covering teachers' formal training to teach, much less their perception of their own skills and abilities in the classroom.

Skinner (1956) stated that college teaching is the only profession for which there is no professional training. University Ph.D. programs in the United States emphasize content and research-related skills, while teaching skills are what are immediately put into practice. Recent literature has seen an increase in the area of teaching the teacher how to teach. Walstad and Becker (2003) stated that "Teaching a course or leading a recitation section is an important instructional duty that, if not handled well, can hurt a department by increasing student complaints, decreasing majors, and negatively affecting employment." Marx et al. (2016) suggested that the the world's largest business accreditation agency, the Association to Advance Collegiate Schools of Business (AACSB) International, cultivate teaching accountability standards of business doctoral programs. There are other academics that believe a more restrained approach to accreditation standards is warranted (Lewicki \& Bailey, 2016). Regardless, SUNY Buffalo State has seen the need to improve teacher performance in the classroom as an effectiveness and student retention effort. Since accreditation changes are not imminent, the change must be at a personal, and eventually college-wide, level.

Academia creates a tension which sociologist Jodi O'Brien (2006) called "schizophrenic state of academe." Colleges and universities stress the importance of one third teaching, one third scholarship, and one third service, when, in reality, faculty members know that research is the primary area of responsibility, especially when striving for tenure and promotion. Irby (2013) stated that becoming effective teachers does not distract from scholarship. Instead, it enhances scholarship by enabling researchers to use appropriate terms and examples needed communicate clearly and effectively. While teaching and scholarship should be mutually reinforcing, junior faculty especially internalize that publications and grants are the accomplishments that are highlighted in reaching tenure and promotion. 


\section{Master Educator Program (MEP) at SUNY Buffalo State}

\subsection{Purpose of Study}

Examples of teacher training are emerging. The faculty of the School of Agriculture of the Pennsylvania State College enacted a project called "Teaching College Professors to Teach" in which ten lessons were given during a one-week program by Dr. William Kilpatrick of Teachers College, Columbia University. In addition, LEGO Education has a U.S. Education Masters Educators program, in which early learning and high school educators use LEGO solutions to enable success of students via hands-on learning experiences (Powers, 2019). At SUNY Buffalo State, the Master Educator Program (MEP) was developed and commenced in September 2018, with the first cohort at the end of its two-year term. The mission of the program is as stated, "By enlisting Master Educators as agents of change, our ultimate goal is to organically grow an extraordinary culture within the School of Professions for both faculty and students" and the vision is "To provide every School of Professions major with a transformative educational experience that inculcates and inoculates them with 21 st century skills." In short, the program aims to future-proof every student. The School of Professions hopes to eventually achieve national acclaim for educational practices that successfully close the gap between 21 st century workplace demands and a 21 st century education.

The program was developed as an action step out the most recent strategic plan. A cohort of six professors was chosen amongst the elite teachers within the School of Professions. Each of these professors was paired with an instructional coach from the School of Education. In year one, the cohort and the coaches attended monthly training modules including: foundation setting, emotional intelligence, high-leverage practices, high-impact practices, classroom management, 21st century skills, understanding today's students, creative thinking, and utilizing technology. Coaching sessions between each coach and mentee were established based on an individual basis and need. Summary of the modules included: 1) techniques for understanding our current generation of students, and how they learn and apply knowledge, 2) the skills that employers are seeking in students and ways to bridge that gap, ensuring students are exiting university with a skill set that makes them employable and successful in the current work force, and 3) incorporating the content from the previous areas into our courses in an effective manner that engages students and facilitates learning. In year one, each cohort member was responsible for implementing, at a minimum, one educational approach into one class. The level and degree of implementation varied across cohort members. An example of a course implementation plan for year one can be seen in Appendix A.

Year two of the program continued to add training, while focusing on readying the cohort to transition from mentee to mentor in year three. Year two modules included: teaching 
practices, mentoring, classroom management, distance learning and related technology (amid the Covid19 pandemic), leadership practices, and, finally, a closeout celebration. Experts in each of the content areas acted as instructors and facilitators. The cohort used the class sessions to practice skills, which were then applied outside of the classroom. An array of techniques was applied within their courses. Learnings from the applications were shared amongst the cohort and with the university and leadership board. Cohort two recruitment is now in process and will cross all schools within the university.

Coaching may have different degrees of formality and structure. Facilitative coaches see coachees as equals who make most, if not all, decisions during coaching. Directive coaches are the opposite, and strive to transfer knowledge to the coachee. The dialogical coach uses a balance of advocacy and inquiry. They ask insightful questions while imparting their knowledge. This coaching style has been found to be an effective model between our colleagues. By creating a model in which designated space and times were established for coaches and coaches to come together to solve problems and to share teaching experiences, we are creating a culture that recognizes the importance of teaching and support networks. The formal peer mentorships provide the School of Professions faculty with accessible resources for teaching-related questions, modeling, and techniques. To our knowledge, no other post-secondary institutions have adopted a model of teacher training that includes a peer-to-peer coaching model.

\subsection{Methodology}

As an initial study, final grades, both in whole and by grading category, were captured before and after implementation of educational strategies $(\mathrm{k}=2)$. The sample size $(\mathrm{n})$ per group ranged from 38 to 77 . Use of ANOVA is appropriate if $\mathrm{n}-\mathrm{k}>0$. In addition, the number of A's through F's given per semester were also captured. Grades were analyzed using Analysis of Variance (ANOVA) techniques, comparing each of the graded means of sections before and after implementation. However, the ANOVA does not tell you where the difference lies, thus a t-test was conducted to test each pair of means.

\subsection{Results}

Based on the ANOVA results in table 1, the null hypothesis can be rejected at the $5 \%$ level, and we can conclude that the means are not all equal, indicating that there was a difference between the means of the three semesters of data captured. 
Table 1. ANOVA Results

\begin{tabular}{lcccccc}
\hline Source of Variation & SS & df & MS & F & P-value & F crit \\
\hline Between Groups & 30495.47 & 7 & 4356.49 & 204.29 & $1.95 \mathrm{E}-14$ & 2.66 \\
Within Groups & 341.19 & 16 & 21.32 & & & \\
Total & 30836.66 & 23 & & & \\
& & & & & \\
\hline \multicolumn{5}{l}{ Source: Mathien (2020) }
\end{tabular}

The t-tests were used to test the null hypothesis that the means of two populations are equal. T-tests were conducted across all pairs of means, and found to be insignificant at the 5\% level for all pairs; therefore, we fail to reject the null hypotheses that the means are equal for all pairings. When testing the last two semesters, when the most changes were implemented, at the $10 \%$ level, the results were found to be partially significant, thus we are unable to conclusively reject or fail to reject the null hypothesis at this level. The results from this test can be seen in table 2 .

Essentially, an ANOVA provides a statistical test to determine if the means of several groups are all equal and, as a result, generalizes t-test to more than two groups. The t-test is used when determining whether two averages or means are the same or different. An ANOVA can be more useful than a two-sample t-test as it has a lesser chance of committing a type I error. The ANOVA is preferred when comparing three or more averages or means. A t-test has more odds of committing an error the more means are used, which is why ANOVA is used when comparing two or more means.

While the results are inconclusive and do not support statistical changes in the overall averages between semesters, when looking at the ANOVA results or when looking at the raw data, means in all areas are improved after implementation of MEP techniques. The final semester is also the first semester is which no students failed the course. Student qualitative feedback was also consistent with improvement satisfaction of the course.

\section{Conclusion and Recommendations}

Learning to be an effective educator is an ongoing process. The academic model that doctoral students encounter in their Ph.D. programs is limited, and the students that they ultimately teach are typically quite different than the students in their program. Many new faculty assume they will be teaching dedicated, academically-oriented students, and are often surprised to find students who have trouble with writing papers and reading, and many who have little enthusiasm for learning. It is important for educators to develop strategies for engaging $21^{\text {st }}$ century students. 
Table 2. T-Test Results

\section{Compare Means (Spring 2019 to Fall 2019)}

\begin{tabular}{|c|c|c|c|c|c|c|}
\hline \multicolumn{7}{|l|}{ Descriptive Statistics } \\
\hline VAR & $\mathrm{N}$ & Mean & Std Dev & Var & Min & Max \\
\hline Final Grades Spring 2019 & 77 & 81.98 & 16.99 & 288.85 & 0 & 98 \\
\hline Final Grades Fall 2019 & 38 & 87.47 & 16.44 & 270.29 & 0 & 98.15 \\
\hline \multicolumn{7}{|c|}{ t-test assuming unequal variances (heteroscedastic) } \\
\hline Hypothesized Mean Difference & 0 & & & & & \\
\hline Mean Difference & -5.48 & & & & & \\
\hline Variance (Welch-Satterthwaite) & 282.77 & & & & & \\
\hline Test Statistic & 1.66 & & & & & \\
\hline Degrees of Freedom & 76 & & & & & \\
\hline
\end{tabular}

H1: Mu1 - Mu2 $\neq 0$ / Not equal (two-tailed)

t Critical Value (10\%) $\quad 1.66 \quad$ p-value $\quad 0.10 \quad$ H1 (10\%) $\quad$ Rejected

H1: Mu1 - Mu2 < 0 / Less than (lower-tailed)

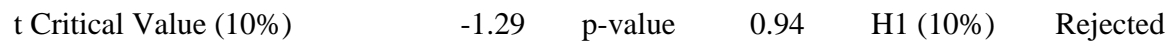

H1: Mu1 - Mu2 > 0 / Greater than (upper-tailed)

$\begin{array}{lllll}\text { t Critical Value (10\%) } & 1.29 & \text { p-value } & 0.05 & \text { H1 (10\%) }\end{array}$ 
Developing institutional support for preparing faculty to teach is an important step for both teaching effectiveness and student retention. The MEP is a move to improving student education, creating students that are better prepared to enter the workforce, and faculty members that are supported in their balance of the three pillars of teaching, service, and scholarship.

This study is an initial look at the implementation of educational techniques learned within the MEP across three semesters. Data will continue to be tracked, and future research will also include control variables for overall student GPAs to account for lower admission standards due to decreased enrollment numbers.

\section{References}

Irby, C.A., Fuist, T.N., Rumpf, C., Jackson, C.L., Polasek, P.M., \& Van Altena, A.S. (2013). Teaching Each Other to Teach. Contexts, 12(3), 84-87.

Lewicki, R.J. \& Bailey, J. (2016). A Deeper Dig: Rejoinder to "Isn't It Time We Did Something About the Lack of Teaching Preparation in Business Doctoral Programs?". Journal of Management Education, 40(5), 516-523.

Marx, R.D., Garcia, J.E., Butterfield, D.A., Kappen, J.A., \& Baldwin, T.T. (2016). Isn't It Time We Did Something About the Lack of Teaching Preparation in Business Doctoral Programs? Journal of Management Education, 40(5), 489-515.

O’Brien, J. (2006). "Reorganizing the Contradictions of Teaching and Research.” Pp. 16-38 in Excellent Teaching in the Excellent University edited by Jerome Rabow. Bethesda, MD:Academica Press.

Powers, A. (2019). "LEGO Education Launches An Innovative Teacher's Program." Forbes, February 10, 2019.

Roach, J., Milkman, M., \& McCoy, J. (2014). "Recent business doctorates' teacher training and perceptions of their preparedness to teach business courses." Academy of Educational Leadership Journal, 18(2), 45-60.

Skinner, B.F. (1956). A case history in scientific method. American Psychologist, 11(5), 221-233.

Walstad, W.B. \& Becker, W. (2003). "The Instructional Use and Teaching Preparation of Graduate Students in U.S. Ph.D.-Granting Economics Departments." American Economic Review, 93(2), 449-454. 


\section{Appendix A: Sample Course Implementation Plan (Operations Management)}

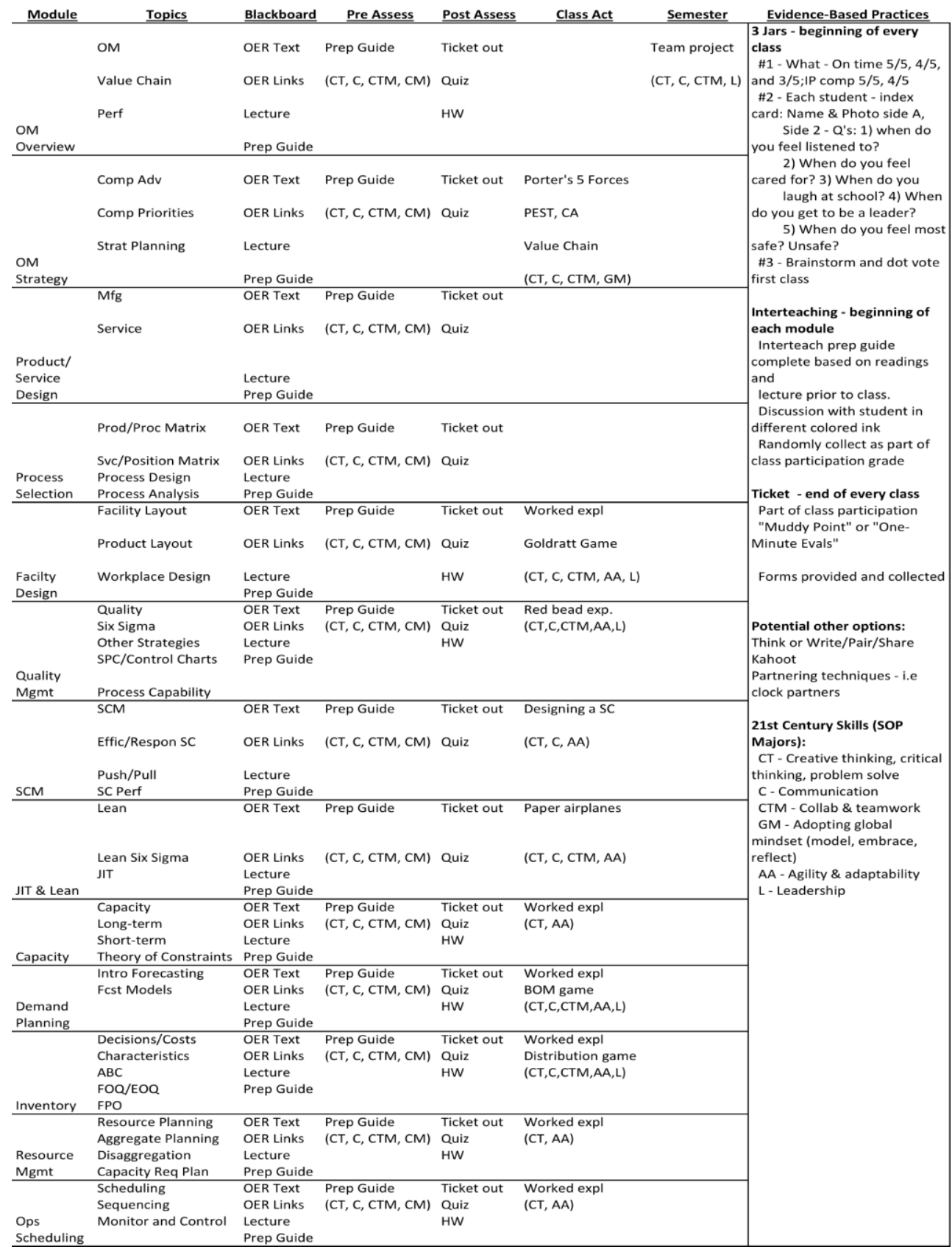

